Journal of Energy and
Environmental Sulial publication of the International Society for Energy, Environment and Sustainability (ISEES)
Journal homepage : www.jees.in

\title{
Carbon Nano Tube Forest on Stainless Steel Mesh as Catalyst Support for Development of Low-cost SCR for Diesel Engine NO Reduction
}

\author{
Akash Kumar, Piyush Avasthi, Gaurav Tripathi, Viswanath Balakrishnan, Atul Dhar* \\ School of Engineering, Indian Institute of Technology Mandi, India, 175005
}

\section{A R T I C L E I N F O}

Received : 20 June 2019

Revised : 28 August 2019

Accepted : 04 October 2019

Keywords:

Diesel engine, $\mathrm{NO}_{\mathrm{x}}$ emissions,

Selective Catalytic Reduction,

CNT, Washcoat, Substrate

\begin{abstract}
A B S T R A C T
It is important to reduce $\mathrm{NO}_{\mathrm{x}}$ emission from diesel engines in order to implement government emission legislation. Selective catalytic reduction (SCR) device is proven as effective technology for reduction of $\mathrm{NO}_{\mathrm{x}}$ emission. However, to develop a compact, light-weight, economical and efficient SCR especially for low temperature range is still a challenge. Therefore, the present work investigates the application of carbon nano tube (CNT) washcoat for reduction of $\mathrm{NO}_{x}$ through SCR. Support used in this investigation is made of commercially available stainless steel wire mesh. Cost of commercially available catalytic converter is very high due to use of the noble metal catalyst and alumina as the substrate material. In this study, low cost substrate made of stainless steel wire mesh is used as support material on which carbon nanotubes are used as washcoat to enhance its catalytic performance. Here, base metal oxides are used as catalyst with small amount of Pd. At $4 \%$ catalyst loading, CNT on stainless steel (SS) mesh resulted in $1.4 \%$ and $2.9 \%$ higher $\mathrm{NO}_{\mathrm{x}}$ reduction $(98.15 \%)$ than bare $(96.76 \%)$ and $\mathrm{Al}_{2} \mathrm{O}_{3}(95.35 \%)$ on $\mathrm{SS}$ mesh.
\end{abstract}

(C) 2020 ISEES, All rights reserved

\section{Introduction}

For reducing $\mathrm{NO}_{\mathrm{x}}$ emissions many in-cylinder combustion improvement techniques (Kumar et al., 2017) (Sindhu et al., 2017) as well as after treatment methods are being explored. $\mathrm{NO}_{\mathrm{x}}$ conversion efficiency, rate as well as back pressure in the automobile exhaust line are highly dependent on substrate, washcoat and catalyst used for $\mathrm{NO}_{x}$ reduction. For heterogeneous catalysts, structured support reactors have clear advantage over the conventional slurry and fixed bed reactors (Nijhuis et al., 2001)(Hernández-garrido et al., 2015). At large scale, monolith structured support shows lower pressure drop, offers uniform flow distribution and shorter residence time (Minett et al., 2013)(Gong et al., 2008). These monolith structures either made of ceramics (mainly cordierite) or metallic materials (stainless steel, metal alloys, etc.) consist of single block of small $(0.5-4 \mathrm{~mm})$ parallel channels with a catalytic wall. Mostly cordierite (a ceramic material consisting of magnesia, silica, and alumina in the ratio of 2:5:2) is used as monolithic structures in automotive industries for exhaust gas after treatment (Bansal and Bandivadekar, n.d.)(Buckingham et al., 1990)(Rodríguez et al., 2016)(Li et al., 2013). Ceramics monolith also show several disadvantages such as low thermal conductivity, nonporous walls between the two adjacent channels, risk of brittle cracking under the rapidly changing pressure, lower surface area, thickness of wall limited upto $1 \mathrm{~mm}$, complex design and higher cost etc (Tomasic and Jovik, 2006)(Sanz et al., 2016).

The aim of the study is to develop a low-cost substrate where CNTs are used as washcoat materials and SS-304 grade wire mesh (300 pores per inch) is used as structured support material. CNTs have been chosen as catalyst supports due to their high absorptivity, controllable mesoporosity and specific metal support interactions result into improved catalytic activity and selectivity (Xu et al., 2016)(Peigney et al., 2014)(Labhsetwar et al., 2006). CNTs used as washcoat materials show lower pressure drop in comparison with commercially used alumina washcoat material. Washcoat materials should have large surface area and high porosity. Wang et al. and Singh et al. have reported a significant increase of Brunauer Emmett Teller (BET) surface area and pore volume after the growth of carbon nanotubes (Wang et al., 2006)(Singh et al., 2002). Thermal characterization shows that CNT grown SS-mesh substrate is thermally stable up to $500^{\circ} \mathrm{C}$ (Bom et al., 2002)(Landström, 2016). Thermal conductivity of CNTs also helps in maintaining the temperature of reaction and improves the durability of washcoat material (Merino et al., 2017). So this substrate is suitable for low-temperature catalytic reactions at low cost. Minett et al. used CNT as a washcoat material by growing CNTs on ceramics monolith support of diameter $1 \mathrm{~cm}$ and length $10 \mathrm{~cm}$ (Minett et al., 2013). For large scale reactions, the pressure

\footnotetext{
* Corresponding Author: : add@iitmandi.ac.in
} 
drop has a key role in work efficiency. The author claims that if CNTs are used as washcoat materials over a ceramic monolith support, the pressure drop is reduced. CNTs are used as washcoat materials with support material for large flow rate of gases in the catalytic reactor. It shows less pressure drop resulting in a lower power requirement. Wang et al. recently reported $\mathrm{Mn}-\mathrm{Cr}$ catalyst for selective catalytic reduction of Nitric oxide at low temperature (Wang et al., 2018)Kalam et al. studied a new catalytic converter (catco) for natural gas fuelled engine (Kalam et al., 2008). They compared their performance with commercial catalytic converters with honeycomb ceramic substrate and noble metals catalyst. It is experimentally found that the conversion efficiencies of $\mathrm{TiO}_{2} / \mathrm{CoO}$ based catalytic converter are $93 \%, 89 \%$ and $82 \%$ for $\mathrm{NOx}, \mathrm{CO}$, and $\mathrm{HC}$ emissions respectively. It was found that $\mathrm{TiO}_{2} / \mathrm{CoO}$ base catalytic converter reduces $\mathrm{NO}_{x}, \mathrm{CO}$ and $\mathrm{HC}$ emissions by $24 \%, 41 \%$ and $40 \%$, respectively with reference to OEM catco.

This investigation focusses on development of compact and light weight substrate and washcoat for SCR having $\mathrm{NO}_{\mathrm{x}}$ reduction capabilities. Performance of new catalyst system was characterized for NOx reduction by $\mathrm{NH}_{3}$-SCR. In this work we used three different substrates with the same standard catalyst to investigate their catalytic performance for NO reduction in reactor setup with simulated exhaust gas.

\section{Materials and Methods}

\subsection{CNT growth on SS-mesh substrateProperties:}

Three zones CVD furnace (Microphase, Japan) was used to achieve controlled growth of aligned CNT on SS mesh. SS mesh was kept in the third heating zone to synthesize CNTs at $700{ }^{\circ} \mathrm{C}$. Acetylene was used as a carbon precursor and air was used as carrier gas. For sample preparation, $20 \mathrm{~mm}$ width and $1 \mathrm{~m}$ length wire mesh sheet was rolled into a cylinder of $20 \mathrm{~mm}$ diameter and $20 \mathrm{~mm}$ length. The rolled substrate was cleaned by acetone with ultrasonic bath for 15 minutes. After cleaning, etching was performed with $72 \mathrm{ml} \mathrm{HCL}$ acid for $20 \times 1000 \mathrm{~mm}^{2}$ substrate for 30 minutes. After etching SS substrate, we cleaned it again in acetone in order to remove acid residues followed by drying and loading it in CVD reactor for growing the CNTs. After this, the CVD tube was purged by $\mathrm{Ar}$ with $700 \mathrm{sccm}$ flow rate for 5 minutes. Then the temperature of CVD furnace was ramped up to $850^{\circ} \mathrm{C}$ in 15 minutes with Air flow rate of 592 sccm. Sample was heated at $850^{\circ} \mathrm{C}$, for 30 minutes. After preheating, this etched SS mesh was cooled up to $700{ }^{\circ} \mathrm{C}$ within 15 minutes. After this, acetylene gas was supplied at $45 \mathrm{sccm}$ flow rate for 5 minutes. At the end of acetylene gas supply, SS sample was kept at $700{ }^{\circ} \mathrm{C}$ temperature for 15 minutes for CNT growth. Finally, SS sample was cooled to room temperature. Cooling of the samples resulted in high surface area for CNT growth on SS 304 mesh substrate with $20 \mathrm{~mm}$ diameter and $20 \mathrm{~mm}$ length.

\subsection{Coating of $\mathrm{Al}_{2} \mathrm{O}_{3}$ on $\mathrm{SS}$ mesh support:}

SS mesh support was coated with alumina coating by solution dipping method. For making $0.002 \mathrm{~kg}$ of $\mathrm{Al}_{2} \mathrm{O}_{3}$ solution with Ethanol, $0.008 \mathrm{~kg}$ of Aluminum peroxide in $20 \mathrm{ml}$ of Ethanol, $6.4 \mathrm{ml}$ of $\mathrm{HNO}_{3}$ was mixed for 14400 seconds. In parallel, another mixture of $0.004 \mathrm{~kg}$ of Tri-block- copolymer P $(1,2,3)$ with $40 \mathrm{ml}$ of Ethanol was also mixed for 14400 seconds. Both mixtures were stirred together for 14400 seconds continuously for ensuring homogeneous mixing. After that, the mixture was heated at $60^{\circ} \mathrm{C}$ for 3600 seconds to remove ethanol. Then monolith was dipped into the mixture and purged with $\mathrm{N}_{2}$ at low pressure for opening the pores. The coated monolith was kept in oven for setting and drying. Subsequently, cooling resulted in high surface area for $\mathrm{Al}_{2} \mathrm{O}_{3}$ growth on SS 304 mesh substrate.

\subsection{Coating of catalyst solution on different substrates:}

In this work,sol-gel auto-ignition method is used for coating of $\mathrm{NiFe}_{2}$ ${ }_{x} \mathrm{Pd}_{\mathrm{x}} \mathrm{O}_{4}$ catalyst on substrateswith ethylene glycol as solvent.Same coating method was also used byXu et al. (Xu et al., 2016). After catalyst solution preparation, substrate was dipped into the catalyst solution and kept in the universal oven for drying at $120^{\circ} \mathrm{C}$ for 15 minutes. This process was repeated 3-4 times and finally, the sample was dried in the oven for 7200 seconds at $120^{\circ} \mathrm{C}$. After drying, the sample was transferred to a muffle furnace, and heated at $400^{\circ} \mathrm{C}$ for 14400 seconds.

$\mathrm{NiFe}_{1.93} \mathrm{Pd}_{0.07} \mathrm{O}_{4}$ catalyst was coated on all substrates. It is possible to change the catalyst loading on substrate by playing with dilution of catalyst solution. We estimated the catalyst loading by the weight measurements with respect to total weight of substrate. For low catalyst loading, we diluted catalyst solution by 100 times by adding one drop of solution in $100 \mathrm{ml}$ ethylene glycol $\left[\left(\mathrm{CH}_{2} \mathrm{OH}\right)_{2}\right]$. Different catalysts loading were investigated to understand the role of CNT washcoat over the catalytic performance.

\section{Results and Discussion}

\subsection{Microstructural observations:}

After achieving high surface area CNT growth on SS 304 mesh, firstly all samples were characterized with the help of FESEM. CNT nanotube diameters found to vary ranging from 20 to $70 \mathrm{~nm}$. Preheat treatment at $850{ }^{\circ} \mathrm{C}$ favors the re-crystallization process, and it generates nanometer scale grain structures providing particle like active catalytic sites on SS mesh. In order to achieve large-scale growth of CNT on SS mesh, 2meter long strip is taken and rolled into a concentric cylindrical shape and inserted into the growth zone as shown in figure $1 \mathrm{a}$ and $1 \mathrm{~b}$. Same growth optimizations have been carried out to achieve large area coverage growth. Low magnification SEM image is presented in figure 1c, corresponding high magnification image is shown in figure $1 \mathrm{~d}$, where vertically aligned CNT forest is grown with the height of $\sim 10 \mu \mathrm{m}$. This kind of forest growth is favorable in increasing the surface area which is suitable for the high catalytic activity. After catalyst coating, CNT growth on SS-mesh substrate provide the most suitable kind of porosity and surface area for a heterogeneous catalytic reaction shown in figure $2 a, 2 b$. Due to its large surface area, catalyst can be easily dispraised uniformly over washcoat which enhanced its catalytic performance. According to this, CNT as washcoat material over SS-mesh substrate during catalyst coating, the catalyst material was well dispersed. For comparison SEM images of catalyst coated on SS mesh and $\mathrm{Al}_{2} \mathrm{O}_{3}$ washcoat are presented in figure $2 \mathrm{c}, 2 \mathrm{~d}, 2 \mathrm{e}, 2 \mathrm{f}$,respectively which shows dispersion of catalyst material is not uniform.

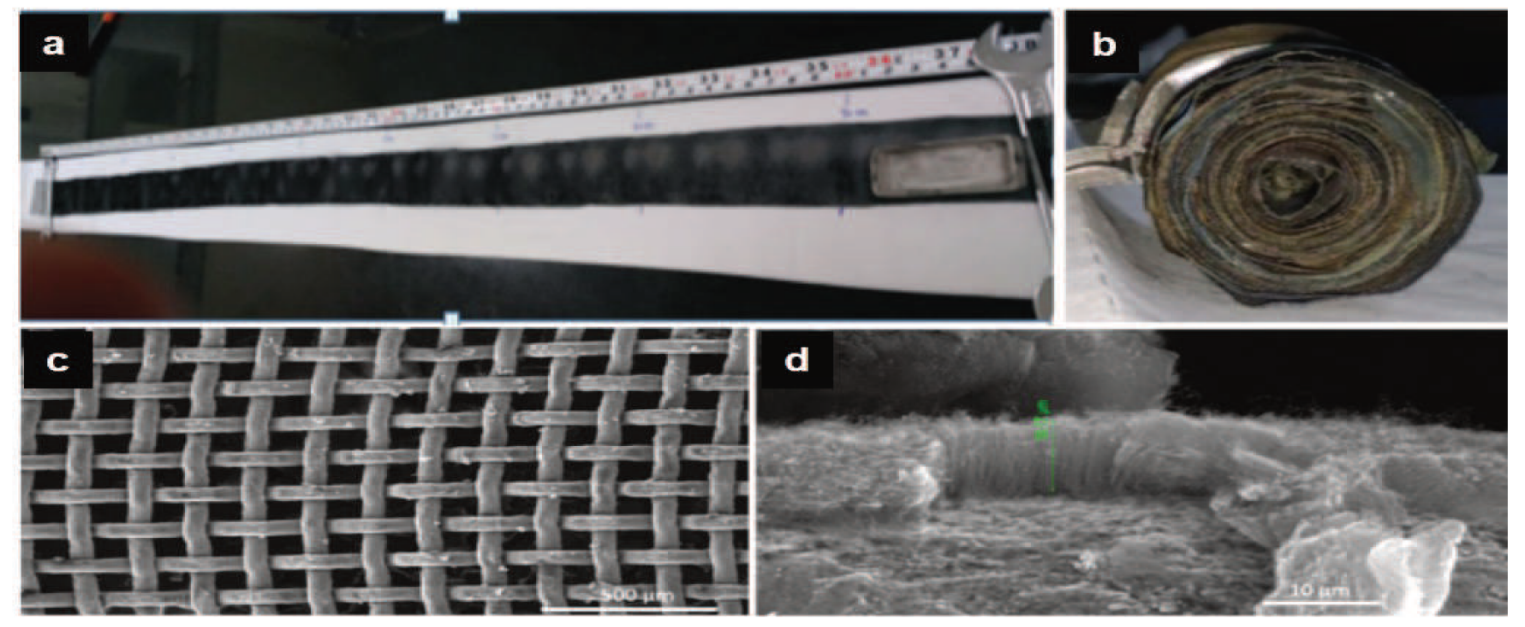

Figure 1. (a) Optical images of CNT on SS mesh showing meter scale growth (b) Optical image showing roll geometry (c) SEM image of aligned CNTs at low magnification (d) corresponding high magnification SEM image showing vertical alignment of CNT's 

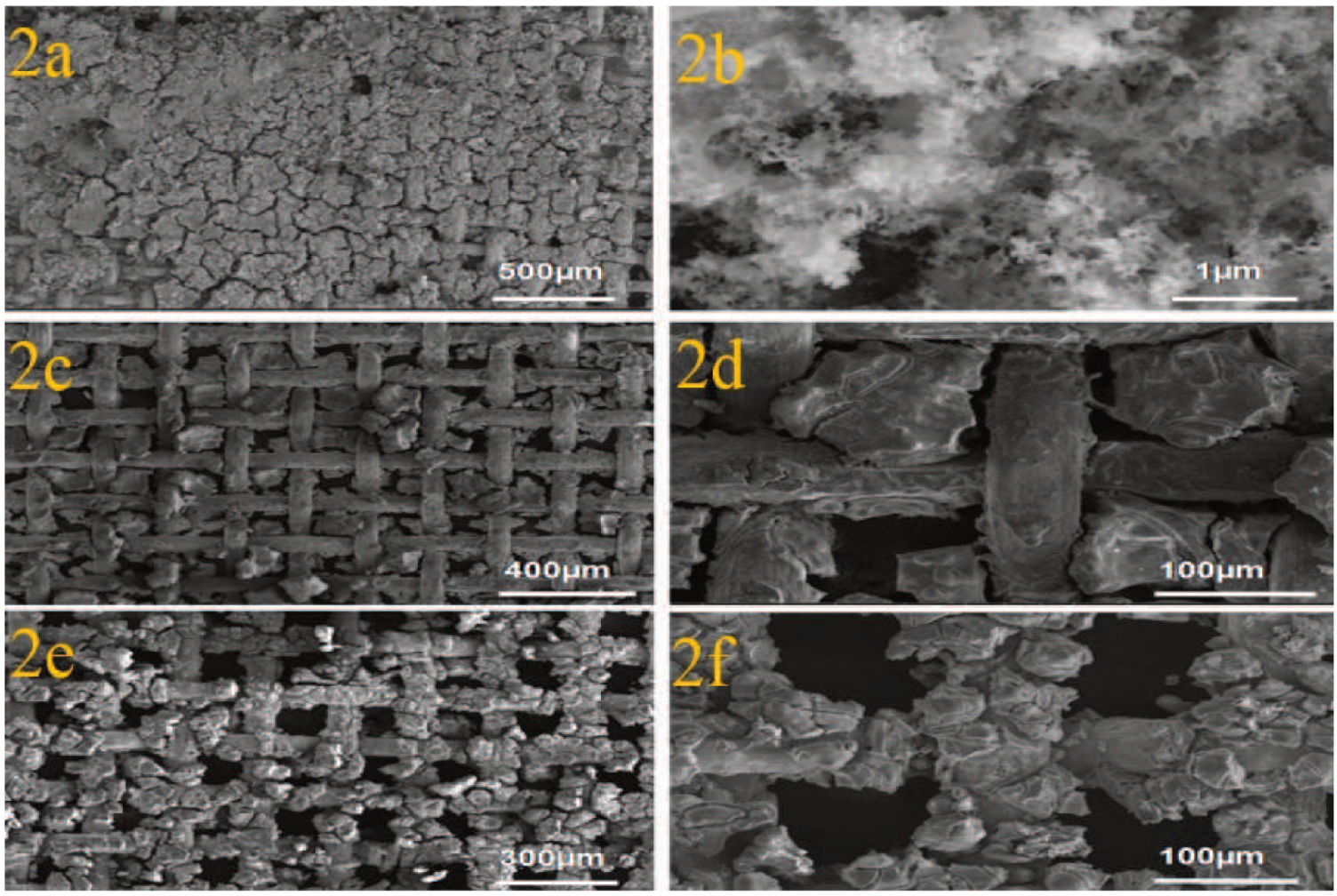

Figure 2. FESEM images after $4 \%$ catalyst coating on all three substrates, (a) and (b) for SS-CNT-NiFePdO (c) and (d) for SS-NiFePdO

Figure 3 represents Raman characterization for CNTs in which the presence of higher frequency (disordered), G (graphite), and 2D (secondorder Raman scattering from D-band variation) modes of CNTs is evident. The ratio of the intensities of $\mathrm{D}$ and $\mathrm{G}$ bands is a good indicator of the quality of samples. Both SWCNT and DWCNT show higher differences in intensities of $D$ and $G$ bands. The $D, G$ and $2 D$ modes are found in graphite, the RBM is specified to CNTs and is representative of the isotropic radial expansion of the tube. The RBM frequency is inversely proportional to the diameter of the tubes.

\subsection{Catalytic activity characterization:}

In this study, we had developed a reactor study setup to investigate the $\mathrm{NO}$ reduction performance for developed $\mathrm{NO}_{\mathrm{x}}$ reducer catalyst coated substrate samples. All SCR activity tests were carried out in this reactor setup. Catalyst coated substrate was placed in middle of quartz tube. In this $\mathrm{NO}$ was introduced from a gas influent mixed stream consisting of $2500 \mathrm{ppm} \mathrm{NO}, 5000 \mathrm{ppm} \mathrm{NH}_{3}$, and $\mathrm{He}$ (helium) used as the balance gas. These gases were fed from compressed gas cylinders. Their flow rates were accounted with the help of rotameters of rating $500 \mathrm{ml} / \mathrm{min}$ and $250 \mathrm{ml} / \mathrm{min}$ for $\mathrm{NO}, \mathrm{NH}_{3}$ respectively. The catalyst loaded substrate was placed in the constant temperature zone of the tubular furnace, where the temperature was maintained with the help of a simple PID controlled thermocouple and heater. After purging of furnace tube by $\mathrm{N}_{2}$ gas for 5 minutes, furnace temperature was raised upto desired value. All NO reduction experiments were done at steady state. Equation (1) was used to calculate the ratio of $\mathrm{NO}$ conversion. Where $[\mathrm{NO}]_{\text {inlet }}$ and $[\mathrm{NO}]_{\text {outle }}$ are the inlet and outlet concentrations of $\mathrm{NO}$ in the gas mixtures at steady state, respectively.

$$
\text { Percentage of NO reduction }=\frac{\left(\left[\mathrm{NO}_{\text {inlet }}\right]-\left[\mathrm{NO} O_{\text {outlet }}\right]\right.}{\left[\mathrm{NO} \mathrm{O}_{\text {inlet }}\right]} \times 100
$$

Following reaction mechanism is used for calculation of NO formation. $\mathrm{NO}_{\mathrm{x}}$ is mainly formed through thermal route. When temperature increases above $1600^{\circ} \mathrm{C}$ the $\mathrm{N}_{2}$ inside the air get activated and form NO as suggested by Zel'dovich (Zel'dovich (1946)) through equation 2, equation 3 and equation 4 .

$$
\begin{aligned}
& N_{2}+O \Leftrightarrow N O+N \\
& N+O_{2} \Leftrightarrow N O+O \\
& N+O H \Leftrightarrow N O+H
\end{aligned}
$$

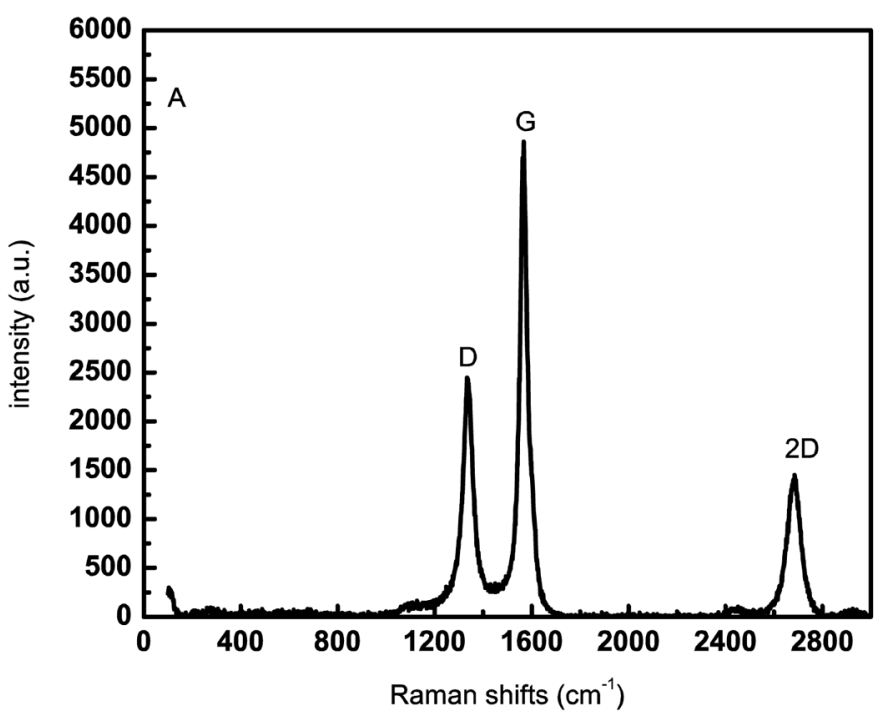

Figure 3. RAMAN characterization for CNT growth SS-mesh

Tedlar bags were used for collecting gas from the outlet port of the reactor setup after catalytic reaction which was characterized by the automotive raw exhaust gas analyzer (AVL, DiTEST CDS 450). After characterization of microstructures, catalytic activity was tested in heated quartz tube reactor. For all measurements, flow rates of $500 \mathrm{ml} /$ minutes for $\mathrm{NO}$ and $250 \mathrm{ml} /$ minutes for $\mathrm{NH}_{3}$ were used. Reactor study is conducted at four different temperatures $325,350,375,400^{\circ} \mathrm{C}$ for all three substrates coated with $4 \%$ of the catalyst. During this test, a rolled SS-mesh sample is used. Figure $5 \mathrm{a}$ shows that $\mathrm{SS}$ mesh-CNT-NiFePdO ${ }_{4}$ catalyst gives $98.15 \%$ reduction, $\mathrm{SS}$ mesh- $\mathrm{Al}_{2} \mathrm{O}_{3}-\mathrm{NiFePdO}$ catalyst gives $95.35 \%$ reduction, SS mesh- $\mathrm{NiFePdO}_{4}$ catalyst gives $96.76 \%$ reduction of $\mathrm{NO}$ with $4 \%$ catalyst loading. This observation indicates the advantage of using $\mathrm{CNT}$ as washcoat material over $\mathrm{Al}_{2} \mathrm{O}_{3}$ washcoat. For studying the effect of pore orientation in conversion efficiency, in next set of 
experiments samples were stacked so that mesh pores became normal to the flow of gases. Hence, in stacked orientation surface area and permeability of washcoat materials play a key role on NO reduction. Thus we tried stacking of samples for catalytic reduction of $\mathrm{NO}$ by $\mathrm{NH}_{3}$ $\mathrm{SCR}$ technology and results are presented in figure $5 \mathrm{~b}$. At lower stack thickness, CNT wash coated samples give better reduction because of its high surface area and permeability for gas flow (figure $5 b$ ). But for thicker stacks, high density of CNT and high loading of catalyst materials blocks reaction sites which results in inferior $\mathrm{NO}$ reduction performance of CNT coated mesh.
Figure $5 \mathrm{~b}$, also shows that 25 stack samples achieved the same NO reduction as rolled samples. In case of stacked samples ( 25 number) only half of the substrate material was used than the rolled substrates. If catalyst loading is less then CNT grown on SS mesh plays a major part for catalytic reduction. To understand the role of CNT grown washcoat, three different catalyst loadings $(0.01 \%, 0.04 \%$, and $0.1 \%)$ were studied (figure 5c). The density for grown CNT on SS mesh was also reduced by reducing $50 \%$ acetylene flow rate during $\mathrm{CNT}$ growth process.

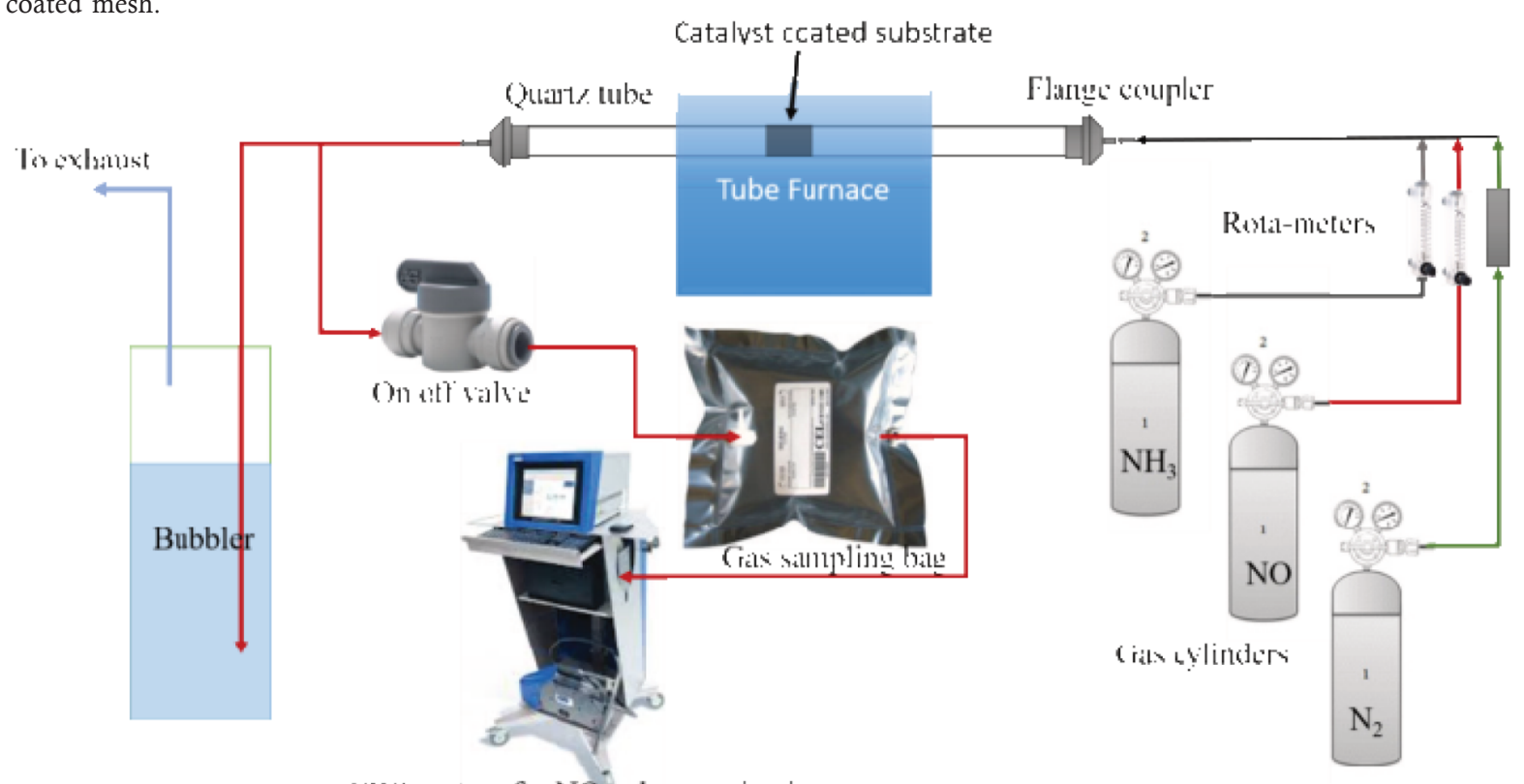

('I)s wistem for Nox chareterizatin

Figure 4. Reactor setup for $\mathrm{NOx}$ reduction by $\mathrm{NH}_{3}-\mathrm{SCR}$

(a)

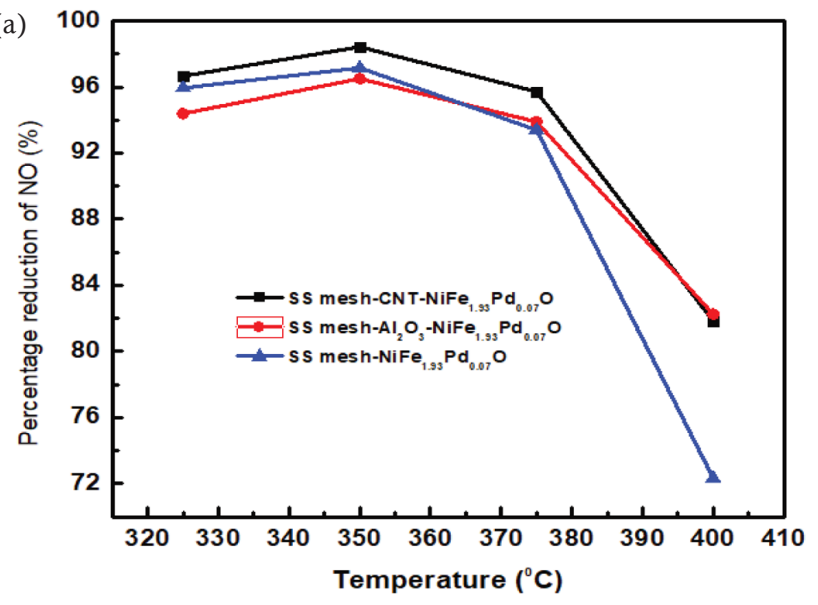

(b)

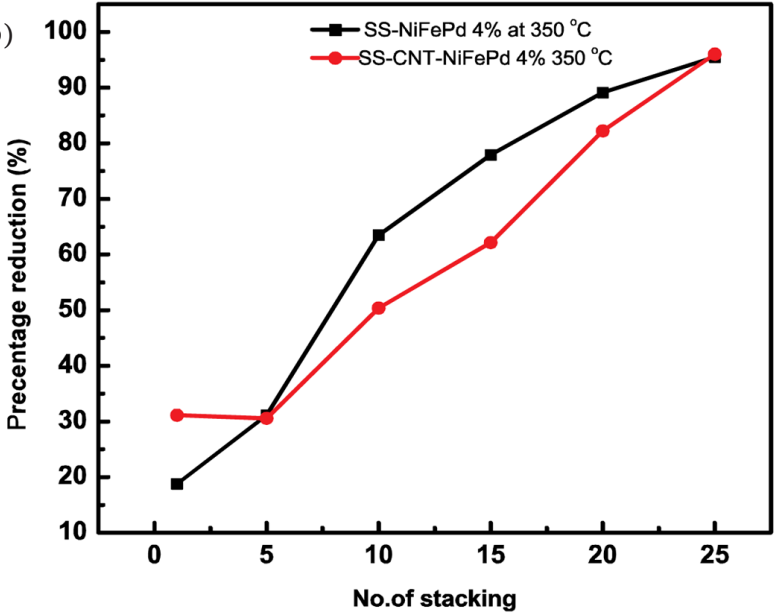

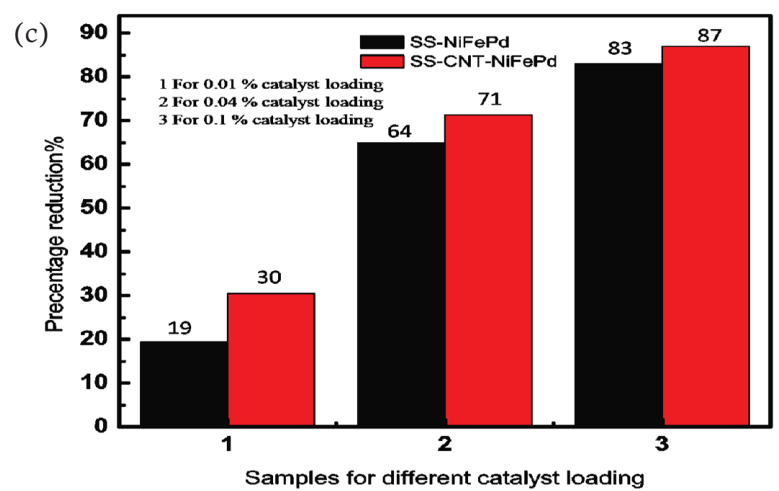

Figure 5. Percentage reductionof $\mathrm{NO}$ at (a) different temperatures by rolled samples of SS mesh-CNT-NiFePdO ${ }_{4}$ catalyst,

$\mathrm{SS}$ mesh- $\mathrm{Al}_{2} \mathrm{O}_{3}-\mathrm{NiFePdO}_{4}$ catalyst, SS mesh-NiFePdO catalyst with $4 \%$ loading, (b) $350{ }^{\circ} \mathrm{C}$ temperature with varying no of stacking of SS meshCNT-NiFePdO ${ }_{4}$ catalyst, SS mesh- $\mathrm{NiFePdO}_{4}$ catalyst at $4 \%$ catalyst, (c) three different catalysts loadings $(0.01 \%, 0.04 \%, a n d 0.1 \%)$ 
Figure $5 \mathrm{c}$, represents that at $0.01 \%$ catalyst loading CNT grown SS mesh substrate gives $10 \%$ more NO reduction efficiency than bare SS mesh substrate. For $0.04 \%$ catalyst loading CNT grown SS mesh substrate gives $7 \%$ more NO reduction efficiency than bare SS mesh substrate. At $0.1 \%$ catalyst loading we get $4 \%$ increment in NO reduction performance by CNT s grown SS mesh substrate over bare SS mesh substrate. Now we can say that CNT as washcoat material can enhance its NO reduction performance. Role of CNT can be very important where the catalyst materials are very costly like $\mathrm{Pt}, \mathrm{Pd}$, to reduce the catalyst loading.

\section{Conclusions}

In this study low-cost CNT grown on SS wire mesh substrate was developed and characterized for NO reduction performance with $\mathrm{NiFePdO}_{4}$ catalyst. For $\mathrm{NO}$ reduction by $\mathrm{NH}_{3}-\mathrm{SCR}$ over $\mathrm{NiFePdO}_{4}$ catalyst, optimum temperature was $350^{\circ} \mathrm{C}$. TGA characterization shows that CNT grown SS-mesh substrate is thermally stable up to $500^{\circ} \mathrm{C}$ compared with alumina washcoat ceramics monolith, which has thermal stability up to $1200^{\circ} \mathrm{C}$. The substrate is found to be more suitable for lowtemperature catalytic reactions. It can be concluded that high surface area washcoat materials as CNT can reduce the amount of catalyst required. Overall this study will be helpful in reducing the cost of SCR system by replacing the costly catalyst materials like $\mathrm{Pt}, \mathrm{Ru}$, and $\mathrm{Rh}$ with CNT.

\section{Acknowledgement}

The authors gratefully acknowledge the research funding provided by DST-SERB, Government of India through Project No. ECR/2015/ 000135 titled "Study of Synergistic Use of Hydrogen and other Alternative Fuels in a Dual Fuel Engine for Emissions Reduction".

\section{References:}

[1]. Bansal, G., Bandivadekar, A., n.d. Overview of India's Vehicle Emissions Control Program.

[2]. Bom, D., Andrews, R., Jacques, D., Anthony, J., Chen, B., Meier, M.S., Selegue, J.P. 2002. Thermogravimetric Analysis of the Oxidation of Multiwalled Carbon Nanotubes/ : Evidence for the Role of Defect Sites in Carbon Nanotube Chemistry. Nano Lett. 2, 615-619.

[3]. Buckingham, F.P., Ph, D., Associates, M.P.R., 1990. An Overview of Technologies for Reduction of Oxides of Nitrogen From Combustion Furnaces.

[4]. Gong, B., Wang, R., Lin, B., Xie, F., Yu, X., Wei, K., 2008. Preparation of Carbon Nanotubes ( CNTs ) -Cordierite Monoliths by Catalytic Chemical Vapor Deposition as Catalyst Supports for Ammonia Synthesis. Catal. Leteers 122, 287-294. https:/ /doi.org/10.1007/s10562-007-9374-4

[5]. Hernández-garrido, J.C., Gaona, D., María, D., Manuel, J., Vidal, H., Sanz, O., Manuel J., Peiró, F., Juan, J., 2015. Comparative study of the catalytic performance and final surface structure of $\mathrm{Co} 3 \mathrm{O} 4 / \mathrm{La}-\mathrm{CeO} 2$ washcoated ceramic and metallic honeycomb monoliths. Catal. Today 253, 190-198. https://doi.org/10.1016/ j.cattod.2015.01.035

[6]. Kalam, M.A., Masjuki, H.H., Redzuan, M., Mahlia, T.M.I.,Fuad, M.A., Mohibah, M. Halim, K.H., 2008. Development and test of a new catalytic converter for natural gas fuelled engine. SAE Tech. Pap. 01, 1550.
[7]. Kumar, J. T. S, Sharma, T. K., Murthy, K. M., Amba Prasad Rao, G., 2018. Effect of reformed EGR on the performance and emissions of a diesel engine: A numerical study, Alexandria Engineering Journal, 57, 517-525. https://doi.org/10.1016/ j.aej.2017.01.008.

[8]. Labhsetwar, N., Biniwale, R.B., Kumar, R., Rayalu, S., Devotta, S., 2006. Application of supported perovskite-type catalysts for vehicular emission control. Catal. Surv. from Asia 10, 55-64. https://doi.org/10.1007/s10563-006-9005-x

[9]. Landström, A., 2016. Thermal stability of carbon nanotubes and role of intercalation.

[10]. Li, C., Xu, H., Hou, S., Sun, J., Meng, F., Ma, J., 2013. SiC foam monolith catalyst for pressurized adiabatic methane reforming $\mathrm{SiC}$ foam monolith catalyst for pressurized adiabatic methane reforming. Appl. Energy 107, 297-303. https://doi.org/10.1016/ j.apenergy.2013.02.039

[11]. Merino, D., Sanz, O., Montes, M., 2017. Effect of the thermal conductivity and catalyst layer thickness on the Fischer-Tropsch synthesis selectivity using structured catalysts. Chem. Eng. J. 327, 1033-1042. https://doi.org/10.1016/ j.cej.2017.07.003

[12]. Minett, D.R., O’Byrne, J.P., Jones, M.D., Ting, V.P., Mays, T.J., Mattia, D., 2013. One-step production of monolith-supported long carbon nanotube arrays. Carbon N. Y. 51, 327-334. https://doi.org/10.1016/j.carbon.2012.08.060

[13]. Nijhuis, T.A., Beers, A.E.W., Vergunst, T., Hoek, I., Moulijn, J.A., 2001. Preparation of monolithic catalysts. Catal. Rev. Sci. Eng. 43, 345-380. https://doi.org/10.1081/ CR-120001807

[14]. Peigney, A., Laurent, C., Flahaut, E., Bacsa, R., Rousset, A., 2014. Specific surface area of carbon nanotubes and bundles of carbon nanotubes. Carbon N. Y. 39, $507-$ 514. https://doi.org/10.1016/S0008-6223(00)00155-X

[15]. Rodríguez, M.L., Cadús, L.E., Borio, D.O., 2016. VOCs abatement in adiabatic monolithic reactors/ : Heat effects , transport limitations and design considerations Chem. Eng. J. 306, 86-98. https://doi.org/10.1016/j.cej.2016.05.055

[16]. Sanz, O., Velasco, I., Reyero, I., Legorburu, I., Arzamendi, G., Gandía, L.M., Montes M., 2016. Effect of the thermal conductivity of metallic monoliths on methanol steam reforming. Catal. Today 273, 131-139. https://doi.org/10.1016/ j.cattod.2016.03.008

[17]. Singh, E., Srivastava, R., Kumar, U., Katheria, A.D., 2002. Carbon Nanotube/ : A Review on Introduction, Fabrication Techniques and Optical Applications. Nano Lett. 2, 615-619. https://doi.org/10.12691/nnr-4-4-1

[18]. Sindhu, R., Amba Prasad Rao, G., Madhu Murthy, K., 2018. Effective reduction of NOx emissions from diesel engine using split injections, Alexandria Engineering Journal, 57, 1379-1392. https://doi.org/10.1016/j.aej.2017.06.009

[19]. Tomasic, V., Jovik, F., 2006. State-of-the-art in the monolithic catalysts / reactors Appl. Catal. A 311, 112-121. https://doi.org/10.1016/j.apcata.2006.06.013

[20]. Wang, G., Zhang, J., Liu, L., Zhou, J.Z., Liu, Q., Qian, G., Xu, Z.P., Richards, R.M., 2018. Novel multi-metal containing MnCr catalyst made from manganese slag and chromium wastewater for effective selective catalytic reduction of nitric oxide at low temperature. J. Clean. Prod. 183, 917-924.

[21]. Wang, J., Wang, R., Yu, X., Lin, J., Xie, F., Kemei, W., 2006. Preparation and Characterization of Carbon Nanotubes-Coated Cordierite for Catalyst Supports. J. Nat. gas Chem. 15, 211-216.

[22]. Xu, C., Sun, W., Cao, L., Yang, J., 2016. Selective catalytic reduction of nitric oxide by hydrogen over NiFe 2 À x Pd x O 4 catalysts at low temperature. Chem. Eng. J 283, 1137-1144. https://doi.org/10.1016/j.cej.2015.08.089

[23]. Y.B. Zel'dovich (1946). "The Oxidation of Nitrogen in Combustion Explosions". Acta Physicochimica U.S.S.R. 21: 577-628 